ORIGINAL RESEARCH

\title{
Complications of mastectomy for breast cancer in a tertiary care centre in South-west Nigeria Ayoade BA ${ }^{* 1}$, Salami BA${ }^{1}$, Opadeyi E, Adekoya AO $^{1}$, Fatungase $\mathrm{OM}^{2}$
}

${ }^{1}$ Department of Surgery, ${ }^{2}$ Department of Anaesthesia, Olabisi Onabanjo University, Sagamu

*Correspondence: Dr. BA Ayoade, Department of Surgery, Olabisi Onabanjo University, Sagamu, Nigeria. Email: teruayoade@gmail.com, babatunde.ayoade@oouagoiwoye.edu.ng; ORCID - https://orcid.org/0000-0001-6834-9012.

\begin{abstract}
Background: An important aspect of the surgical management of breast cancer is loco-regional control which can be accomplished by either breast conservation surgery or mastectomy.

Objective: To examine the outcome of the operation of mastectomy with respect to the complications of the procedure.

Methods: This is a retrospective study of all the patients who had a mastectomy for breast cancer in a Nigerian tertiary care centre from $1^{\text {st }}$ January 2012 to March 2019. The hospital records of the patients were retrieved. Demographic and relevant clinical characteristics of the patients were extracted.

Results: A total of 77 cases were eligible, 76 women and one man. The age range was 28-76 years. Right mastectomy was performed in $54.5 \%$ cases. Preoperative comorbiditiesincludedobesity(34\%), hypertension $(31.2 \%)$, anaemia $(6.5 \%)$ and Diabetes mellitus (7.8\%). Modified radical mastectomy was done in $51.9 \%$ cases, simple mastectomy in 36.4\%, "Toilet Mastectomy" in 9.1\%, and mastectomy after breast conservation treatment in $2 \%$. Twenty-eight percent of the cases required a blood transfusion, $31.2 \%$ received neoadjuvant chemotherapy while $58.2 \%$ had adjuvant therapy. The complications observed included: haemorrhage (7.8\%), seroma $(9.1 \%)$, flap necrosis $(9.1 \%)$ andtumourrecurrence $(7.8 \%)$. As at the time of the report, $41.6 \%$ were alive, $19.4 \%$ were dead and $39.0 \%$ were lost to follow-up.

Conclusion:The complications of mastectomy were mostly haemorrhage, seroma,and flap necrosis, similar to previous reports from other parts of the world.
\end{abstract}

Keywords: Breast cancer, Chemotherapy, Haemorrhage, Mastectomy, Post-operative complications.

\section{Introduction}

The treatment of breast cancer requires a multidisciplinary approach spanning surgery, radiotherapy, chemotherapy, hormonal therapy, and immunotherapy. The inadequacy or non-availability of other modalities of treatment, on account of lack of equipment and or expertise, makes surgery a principal modality of treatment in the Sub-Saharan African region. [1]

The surgical management of breast cancer involves three principal aspects. The first step is obtaining tissue by needle biopsy or open biopsy, which may be either incisional or excisional. The second aspect is loco-regional control which can be accomplished by either breast conservation surgery or mastectomy 
while the third is the treatment of metastasis including resection, insertion of venous access for chemotherapy, correction of anatomical abnormalities and ablative surgery of endocrine glands.

The concept of breast conservation surgery, despite its attractiveness, is difficult to practice since most of the patients with breast cancer present late, therefore making mastectomy the procedure of choice in operable breast cancer in Sub-Saharan Africa. [2] The various types of mastectomy include the classical radical mastectomy, as described by Halsted, in which the pectoralis minor muscle, axillary lymph nodes and fat are removed, various modifications such as that described by Patey, simple mastectomy, skin-sparing or subcutaneous mastectomy. [3] The operation of mastectomy may be associated with many complications such as seroma, flap necrosis, wound infection, shoulder pain, and oedema of the hand. Some of these complications are preventable. Although mastectomy is a common procedure utilized in the management of breast cancer in the SubSaharan African region,there are few reports on the complications of the procedure from the region.

Therefore, this study was aimed at examining the outcome of the operation of mastectomy with respect to these complications in the local practice.

\section{Methods}

This is a retrospective study of all patients who had a mastectomy for breast cancer at the Olabisi Onabanjo University Teaching Hospital, Sagamu, Nigeria from $1^{\text {st }}$ January 2012 to March 2019. The theatre register and records at the Medical Records Department were searched and the case files of the patients were retrieved. Demographic characteristics such as age, sex, educational status, occupation, marital status, parity, and menstrual status were extracted. Other parameters such as co-morbidities, height, weight, Body Mass Index (BMI), stage of the disease, type of mastectomy, type of drain used, blood transfusion requirement, duration of hospital stay, and complications observed over time were also recorded. The period of follow- up was also noted in each case.

The data were entered into a Data Capture Form. The data were analyzed with SPSS software version 20 by IBM Corporation. The variables were converted to means and standard deviation and proportions for continuous and categorical variables respectively. Statistical comparison of proportions was done using the Chi-Squared test. $P$ values less than 0.05 established statistical significance.

\section{Results}

Ninety-three patients had a mastectomy for breast cancer during the study period but only $77(82.7 \%)$ records were available for review. These 77 comprised 76 females and one male.

The age range was $28-76$ years with a mean of $49.0 \pm 9.0$ years. The duration of hospital admission was 7-64 days with a mean of $16.0 \pm 7.0$ years. Right Mastectomy was performed in $42(54.5 \%)$ patients and Left mastectomy in $35(45.5 \%)$ patients. The preoperative co-morbidities included obesity (34; $44 \%)$, hypertension $(24 ; 31.2 \%)$, anaemia (5; 6.5\%) and Diabetes mellitus (6; 7.8\%) (Table I). 
Table I: Co-morbid factors among breast cancer patients who had mastectomy \#

\begin{tabular}{lll}
\hline \multicolumn{1}{c}{ Conditions } & Frequency & Percentage \\
\hline Anaemia & 6 & 6.5 \\
Diabetes & 7 & 7.8 \\
Hypertension & 24 & 31.2 \\
Obesity & 34 & 44.2 \\
None & 39 & 50.4 \\
Psychosis & 2 & 2.6 \\
Arthritis & 2 & 2.6 \\
Others* & 6 & 6.5
\end{tabular}

*Hiadradenitis supprativa 1, Pulmonary Tuberculosis 1, Uterine fibroids 1, Goitre 1, Breast radiotherapy 1 and Asthma 1. \# Some patients had more than one comorbid factor.

Modified radical mastectomy was performed done in $40(51.9 \%)$, simple mastectomy in 28 $(36.4 \%)$, "Toilet Mastectomy" in 7 (9.1\%) and mastectomy for recurrence following breast conservation treatment in $2(2.6 \%)$.
Blood transfusion was done in 28 (36\%) while neoadjuvant chemotherapy was administered in $24(31.2 \%)$, and adjuvant therapy in 45 (58.2\%). The complications included haemorrhage $(6 ; 7.8 \%)$, seroma $(7 ; 9.1 \%)$, flap necrosis $(7 ; 9.1 \%)$, andrecurrence $(6 ; 7.8 \%)$ as shown in Table II.

Table II. Complications after mastectomy

\begin{tabular}{lll}
\hline Complications & Frequency & Percentage \\
\hline None & 41 & 53.2 \\
Seroma & 7 & 9.1 \\
Flap necrosis & 7 & 9.1 \\
Haemorrhage & 6 & 7.8 \\
Recurrence & 6 & 7.8 \\
Wound infection & 5 & 6.5 \\
Multiple complications* & 3 & 3.9 \\
Oedema of the arm & 2 & 2.6 \\
\hline
\end{tabular}

${ }^{*}$ Haemorrhage, seroma, and wound infection at once.

Nineteen of the 28 patients who had perioperative blood transfusion had a postoperative complication, whereas only 17 out of 49 patients who did not have blood transfusion had a postoperative complication $\left(x^{2}=7.8, p=0.005\right)$. A comparison of the comorbidities, neoadjuvant chemotherapy, blood transfusion, and complications are shown in Table III. The frequency distribution of the complications and the types of mastectomy performed is as depicted in Table IV. As at the time of the report, $32(41.6 \%)$ were alive, 15 $(19.4 \%)$ were dead and $30(39 \%)$ were lost to follow-up.

\section{Discussion}

Breast cancer surgeries are usually not followed by life-threatening complications, most of which can be managed on Out-patient basis, since the surgeries are usually elective procedures, carried out on relatively fit patients without traversing major body cavities such as the chest, and abdomen. [4]

In the present study, as expected, there were no mortalities and the spectrum of complications observed was similar to the observations of Ogundiranet al from Ibadan Nigeria, El Tamer et al from the United States of America and N'guessam from Cote de Voire. [2,4,5] 
Table III: Relationship between neoadjuvant chemotherapy, obesity, co-morbidities, and perioperative blood transfusion and postoperative complications.

\begin{tabular}{|c|c|c|c|c|c|c|c|c|c|}
\hline $\begin{array}{l}\text { Co- } \\
\text { morbidities }\end{array}$ & Haemorrhage & $\begin{array}{l}\text { Multiple } \\
\text { Complic } \\
\text { ations }\end{array}$ & None & Seroma & $\begin{array}{l}\text { Wound } \\
\text { infection }\end{array}$ & $\begin{array}{l}\text { Flap } \\
\text { Necrosis }\end{array}$ & Recurrence & $\begin{array}{l}\text { Arm } \\
\text { Oedema }\end{array}$ & $\begin{array}{l}\text { Total } \\
(\%)\end{array}$ \\
\hline \multicolumn{10}{|l|}{ NCT } \\
\hline Yes & 2 & 0 & 12 & 3 & 0 & 2 & 3 & 2 & $24(31)$ \\
\hline No & 4 & 3 & 29 & 4 & 5 & 5 & 3 & 0 & $\begin{array}{l}53(69) \\
77(100)\end{array}$ \\
\hline \multicolumn{10}{|l|}{ Obesity } \\
\hline Yes & 4 & 2 & 18 & 5 & 1 & 4 & 0 & 0 & $34(44)$ \\
\hline No & 2 & 1 & 23 & 2 & 4 & 3 & 6 & 2 & $\begin{array}{l}43(56) \\
77(100)\end{array}$ \\
\hline \multicolumn{10}{|l|}{ Blood } \\
\hline \multicolumn{10}{|l|}{ Transfusion } \\
\hline Yes & 6 & 3 & 9 & 2 & 2 & 3 & 2 & 1 & $28(36)$ \\
\hline No & 0 & 0 & 32 & 5 & 3 & 4 & 4 & 1 & $\begin{array}{l}49(64) \\
77(100)\end{array}$ \\
\hline \multicolumn{10}{|l|}{ Anaemia } \\
\hline Yes & 1 & 0 & 3 & 0 & 1 & 0 & 0 & 0 & $5(6.5)$ \\
\hline No & 5 & 3 & 38 & 7 & 4 & 7 & 6 & 2 & $\begin{array}{l}72(93.5) \\
77(100)\end{array}$ \\
\hline \multicolumn{10}{|l|}{ Diabetes } \\
\hline Yes & 0 & 0 & 4 & 0 & 1 & 1 & 0 & 0 & $6(7.8)$ \\
\hline No & 6 & 3 & 37 & 7 & 4 & 6 & 6 & 2 & $\begin{array}{l}71(92.2) \\
77(100)\end{array}$ \\
\hline \multicolumn{10}{|l|}{ Hypertension } \\
\hline Yes & 1 & 1 & 14 & 4 & 1 & 3 & 0 & 0 & $24(31)$ \\
\hline No & 5 & 2 & 27 & 3 & 4 & 4 & 6 & 2 & $53((69)$ \\
\hline Total (\%) & $6(7.8)$ & $3(3.9)$ & $41(53)$ & $7(9.1)$ & $5(6.5)$ & $7(9.1)$ & $6(7.8)$ & $2(2.6)$ & $77(100)$ \\
\hline
\end{tabular}

Table IV: Type of mastectomy and frequency of complications

\begin{tabular}{llllllllll}
\hline Procedure & Haemorrhage & $\begin{array}{l}\text { Multiple } \\
\text { Complications }\end{array}$ & None & $\begin{array}{l}\text { Serom } \\
a\end{array}$ & $\begin{array}{l}\text { Wound } \\
\text { infection }\end{array}$ & $\begin{array}{l}\text { Flap } \\
\text { Necrosis }\end{array}$ & Recurrence & $\begin{array}{l}\text { Arm } \\
\text { Oedema }\end{array}$ & $\begin{array}{l}\text { Total } \\
(\%)\end{array}$ \\
\hline MRM $^{*}$ & 3 & 1 & 23 & 6 & 2 & 4 & 1 & 0 & $40(52)$ \\
$\begin{array}{l}\text { Simple } \\
\begin{array}{l}\text { Mastectomy } \\
\text { 'Toilet }\end{array}\end{array}$ & 2 & 2 & 12 & 1 & 3 & 2 & 4 & 2 & $28(36.3)$ \\
$\begin{array}{l}\text { Mastectomy' } \\
\text { Mastectomy } \\
\text { after BCT }\end{array}$ & 0 & 0 & 6 & 0 & 0 & 0 & 0 & 0 & $7(9.1)$ \\
\hline
\end{tabular}

*MRM Modified Radical Mastectomy** BCT Breast Conservation Treatment

Co-morbidities are known to contribute to post-operative mastectomy wound complications. ${ }^{[4-6]}$ In the present study, about half of the study population had one comorbidity or more with obesity and hypertension being predominant.

Modified radical mastectomy was the most frequently performed surgery in the cohort of patients studied, with the aim of loco-regional control which is the usual practice in the subregion. [2,5] However less extensive procedure of simple mastectomy was done for some of the cases and this was followed by adjuvant chemotherapy. Sometimes, patients present with huge fungating tumours which can be resected as a palliative measure, a procedure termed 'Toilet Mastectomy' or 
palliative mastectomy. This was done in $9.1 \%$ of the patients in this series.

Perioperative blood transfusion in breast cancer patients has been associated with poor outcome in some studies ${ }^{[7]}$ while other studies reported no effect. ${ }^{[8]}$ In the present study, 36\% of the patients had a perioperative blood transfusion and 19 out of 28 who were transfused had a postoperative complication. This observation seems to suggest perioperative blood transfusion contributes to postoperative morbidity. On the contrary, only 17 out of 49 patients who did not receive blood transfusion had a postoperative complication.

Neoadjuvant chemotherapy had been associated with postoperative wound complications of mastectomy in the past but recent studies showed no increase in postoperative morbidity. ${ }^{[9,10]}$ In the present study, 31\% had neoadjuvant chemotherapy and half of them had a postoperative complication. Seroma, which is the accumulation of serum-like material under the skin flaps and the axilla, is a common complication of mastectomy especially when axillary dissection has been done. It was observed in $9.1 \%$ of the patients in this study and occurred more in patients who had modified radical mastectomy, a procedure involving axillary dissection. This observation is similar to what was observed at Ibadan by Ogundiran et al [2] and N'guessan in Abidjan. ${ }^{[5]}$

Flap necrosis and wound infection occurred in $9.1 \%$ and $6.5 \%$ of patientsrespectively. These two complications are responsible for the long duration of hospital stay as reported in this study since the patients were retained until satisfactory progress was made. One of the patients with flap necrosiswho had a mastectomy for local recurrence following wide local excision and breast radiotherapy was on admission for 64 days. This is not surprising as radiotherapy is known to adversely affect wound healing. The wound infection rate and flap necrosis rate was higher in the present study compared to that reported
byOgundiran et al, [2] and El- Tamer ${ }^{[4]}$ who reported $4.4 \%$, and $4.3 \%$ infection rates respectively.

Bleeding necessitating blood transfusion perioperatively is not uncommon duringor immediately aftermastectomy as this was recorded among $7.8 \%$ of the cohort in this study. Though local recurrence is strictly not a 30-day postoperative complication, it signifies treatment failure.In the present study, $7.8 \%$ of patients had local recurrence most of whom had a simple mastectomy. This observation is not unexpected as some of the patients required post-operative radiotherapy which was not available.Surprisingly, the patients who had "Toilet mastectomy" for fungating lesions suffered little postoperative wound complications and their wounds healed primarily. Also, no recurrence was observed in this group probably as a result of their short survival.

The overall complication rate in the present study was higher than that observed in Ibadan by Ogundiran et al, [2] and Bowen et al [10] in which complications were limited to 30 days postoperative period so did not include late complications such as recurrence andupper limb oedema but similar to the report of $\mathrm{N}^{\prime}$ guessam et al. ${ }^{[5]}$

As at the time of this report, $41.6 \%$ of the patients were alive having been followed up for at least six months, while $39 \%$ were lost to follow-up care and $19.4 \%$ were dead. This pattern is similar to the experience of others. The retrospective nature of the study with attendant missing information, relatively small sample size with lack of powerand absence of survival data are acknowledged as limitations to the study.

\section{Conclusion}

The most frequently observed complications of mastectomy included seroma, flap necrosis, 
haemorrhage, and tumour recurrencesimilar to what is known in other parts of the world.

Authors' Contributions: ABA conceived and designed the study, participated in data collection, analysis, interpretation, literature search and drafting the manuscript. SBA participated in data collection, analysis, and review of the manuscript. $\mathrm{OE}$ and $\mathrm{AAO}$ participated in data collection and review of the draft manuscript. FOM participated in data collection, analysis, and review. All the authors approved the final version of the manuscript.

Conflict of Interest: None.

Funding: Self-funded.

Publication History: Submitted 28 November 2019; Accepted 02 March 2020.

\section{References}

1. El Saghir NS, Adebamowo CA, Anderson BO, Carlson RW, Bird PA, Corbex M. Breast cancer management in low resource countries (LRCs): consensus statement for the Breast Global Health Initiative. Breast 2011; 20 (Suppl.2): S3-S11.

2. Ogundiran TO, Ayandipo OO, Ademola $\mathrm{AF}$, Adebamowo CA. Mastectomy for management of breast cancer in Ibadan Nigeria. BMC Surg 2013; 13: 59. doi:10.1186/1471-2482-13-59.

3. Farquharson M, Hollingshead J, Moran B.Surgery of the Breast. In: Farquharson M, Hollingshead J, Moran B. (Editors) Farquharson's Textbook of Operative General Surgery. 10 $10^{\text {th }}$ Edition. CRC Press. 2015: $31-43$.

4. El-Tamer MB, Marie Ward B, Schiffner T, Neumayer L, Khuri S, Henderson W. Morbidity and mortality following breast cancer surgery in women. National Benchmarks for Standards of Care. Ann Surg 2007; 245: 665-671.

5. N'guessan YI, DiaLamine J, Moctar T, Corneille ST, Gilbert TS, Adunfe OM. et al. Review of mastectomy in the Department of Gynaecology at The Treichville Teaching Hospital, Abidjan- Cote d'Ivoire. Int J Reprod Contracept Obstet Gynecol 2018; 7: 1313-1317.

6. Rostein C, Ferguson R, Cumming KM,Piedmonte MR, Lucey J, Banish A. Determinants of clean surgical wound infections for breast procedures at an oncology center. Infect Control Hosp Epidemiol 1992 ; 13: 207-214.

7. Pysz M. Blood transfusions in breast cancer patients undergoing mastectomy: possible importance of timing. J Surg Oncol 2000; 75: 258-263.

8. Akyol AM, Galloway DJ, George WD. Perioperative blood transfusion does not promote recurrence and death after mastectomy for breast cancer. Br J Surg 1992; 78: 1358-1361.

9. Decker MR, Greenblatt DY, Havlena J, Wikie LG, Greenberg CC, Neuman HB. Impact of neoadjuvant chemotherapy on wound complications after breast surgery. Surg 2012; 152: 382-388.

10. Bowen ME, Mone MC, Buys SS, Sheng X, Nelson EW. Surgical outcomes for mastectomy patients receiving neoadjuvant chemotherapy. A propensitymatched analysis. Ann Surg 2017; 265: $448-456$. 